\title{
Pengaruh Faktor Internal Dan Eksternal Terhadap Kinerja Perbankan Pada Bank Umum Yang Terdaftar Di Bursa Efek Indonesia
}

\author{
Walad Wirawan ${ }^{1}$ \\ Jufrizen $^{2}$ \\ Muis Fauzi Rambe ${ }^{3}$ \\ Program Studi Magister Manajemen, Program Pascasarjana, Universitas Muhammadiyah \\ Sumatera Utara Jalan Denai No. 217,Medan,20371, Indonesia \\ e-mail:waladw@hotmail.com
}

\begin{abstract}
ABSTRAK
Pembangunan infrastruktur di negara Indonesia yang sedang berkembang pesat merupakan salah satu sasaran pembiayaan dari berbagai lembaga keuangan, khususnya lembaga keuangan perbankan.Industri perbankan sendiri memiliki tingkat persaingan yang ketat, sehingga dibutuhkan kinerja yang baik agar dapat menjadi perusahaan yang terdepan dalam bidang bisnisnya.Penelitian ini bertujuan untuk mengetahui pengaruh faktor internal dan faktor eksternal terhadap kinerja perbankan pada bank umum kategori BUKU 4 yang terdaftar di Bursa Efek Indonesia periode 2015-2017.Penelitian ini menggunakan metode asosiatif dengan menggunakan purposive sampling untuk memperoleh data sekunder. Data yang diperoleh diolah menggunakan analisis regresi linier berganda dengan software SPSS 24.Hasil penelitian ini menunjukkan bahwa Capital Adequacy Ratio (CAR), Non-Performing Loan (NPL), dan tingkat inflasi berpengaruh signifikan, sementara Loan to Deposit Ratio (LDR), tingkat pertumbuhan Produk Domestik Bruto (PDB), dan BI Rate tidak berpengaruh signifikan terhadap Return on Asset (ROA), yang dapat dilihat pada model regresi berikut: $\mathrm{ROA}=-5,055+0,308 \mathrm{CAR}+$ 0,022LDR - 1,516NPL + 0,187IHK - 0,052PDB + 0,061BIR.Untuk itu diharapkan, agar bank memperhatikan CAR, LDR, NPL, tingkat inflasi, tingkat pertumbuhan Produk Domestik Bruto, dan BI Rate dalam menjalankan bisnisnya agar memperoleh profitabilitas yang baik.
\end{abstract}

Kata kunci: ROA, CAR, LDR, NPL, Inflasi, PDB dan BI Rate 
Published July 2018

EKONOMIKAWAN : Jurnal Ilmu Ekonomi dan Studi Pembangunan

ISSN : 1693-7600 (Print), ISSN : 2598-0157 (Online), http://jurnal.umsu.ac.Id/index.php/ekawan

\title{
Effect of Internal and External Factors on Banking Performance in Commercial Banks Registered on the Indonesia Stock Exchange
}

\begin{abstract}
The rapidly growing of infrastructure development in Indonesia is one of the financial institutions financing target, especially banking institutions. Banking industry has high level of competition, and needs to perform extremely well in order to be the leader of their business.This research aims to know the effect of internal factors and external factors on bank's performance at commercial banks category 4 (BUKU 4) that listed in Indonesian Stock Exchange.This research uses asosiative method with purposive sampling in order to collect the secondary datas. Those datas are analyzed using multiple linier regression analysis by SPSS 24. The result of this research shows that Capital Adequacy Ratio (CAR), Non-Performing Loan (NPL), and inflation rate have significant impact, meanwhile Loan to Deposit Ratio (LDR), Gross Domestic Product (GDP) growth rate, and BI Rate have non-significant impact on Return on Asset (ROA), which can descibes better on this regression model: $R O A=-5,055+0,308 C A R+$ $0,022 L D R-1,516 N P L+0,187 I H K-0,052 P D B+0,061 B I R$.Therefore, banks need to pay more attention at CAR, LDR, NPL, inflation rate, GDP growth rate, and BI Rate in running their business in order to archieve better profitability.
\end{abstract}

Keywords: ROA, CAR, LDR, NPL, Inflation, GDP and BI Rate

\section{PENDAHULUAN}

Pembangunan infrastruktur di negara Indonesia sedang berkembang pesat. Menurut berita yang dipublikasikan oleh Liputan 6, tercatat ada 30 mega proyek berlabel proyek prioritas hingga tahun 2019 mendatang. Pembangunan infrastruktur tersebut merupakan salah satu sasaran pembiayaan dari berbagai lembaga keuangan, khususnya lembaga keuangan perbankan.

Industri perbankan sendiri memiliki tingkat persaingan yang ketat. Menurut Otoritas Jasa Keuangan (OJK), saat ini ada 99 bank umum yang terdaftar di OJK dan 43 diantaranya listed di Bursa Efek Indonesia (BEI). Karena hal tersebut, bank berlombalomba untuk meningkatkan kinerjanya agar dapat menjadi perusahaan yang terdepan dalam bidang bisnisnya.

Bank menjalankan kegiatan usahanya sebagai fungsi intermediasi yang menghimpun dana masyarakat serta menyalurkannya dalam bentuk kredit. Berdasarkan fungsinya tersebut, bank menjalankan kegiatan usahanya dengan menggunakan dana orang lain, sehingga dibutuhkan kepercayaan publik yang tinggi agar masyarakat menggunakan bank dalam berbagai transaksi keuangannya. 


\section{Published July 2018}

Fing

EKONOMIKAWAN : Jurnal Ilmu Ekonomi dan Studi Pembangunan

ISSN : 1693-7600 (Print), ISSN : 2598-0157 (Online), http://jurnal.umsu.ac.id/Index.php/ekawan

Dari berbagai laporan keuangan tahunan yang dipublikasi oleh perusahaan perbankan, dapat dilihat di neraca bahwa kredit yang direalisasi menduduki porsi yang paling besar dari earning asset bank. Selain itu neraca juga menggambarkan bahwa sumber dana yang digunakan untuk pembiayaan kredit bersumber dari dana masyarakat.

Sebagian bank telah mengupayakan agar pendapatan utamanya bersumber dari fee based income, mengingat bahwa pelemparan kredit merupakan suatu bisnis yang berisiko, dimana selalu ada kemungkinan kredit yang direalisasi menjadi macet (kredit tidak tertagih ( bad debt). Namun pada kenyataannya hampir seluruh perusahaan perbankan di Indonesia mengandalkan pendapatan bunga kredit (interestrevenue) sebagai sumber pendapatan utama. Hal inilah yang menjadi alasan terjadinya persaingan yang ketat di industri perbankan.

Bank dapat diklasifikasikan berdasarkan beberapa kelompok, salah satunya berdasarkan modal inti atau biasanya disebut Bank Umum berdasarkan Kegiatan Usaha (BUKU). Berdasarkan Peraturan Otoritas Jasa Keuangan Nomor 6/POJK.03/ 2016 tentang Kegiatan Usaha dan Jaringan Kantor Berdasarkan Modal Inti Bank, bank dapat dikelompokkan menjadi : Bank Umum Kegiatan Usaha (BUKU) 1, 2, 3, dan 4.

\section{Tabel 1}

Pengelompokan Bank Umum Berdasarkan Modal Inti

\begin{tabular}{ccccc}
\hline Jenis Bank & Jumlah Bank & Prese ntase & Jumlah Kantor & Prese ntase \\
\hline BUKU 1 & 15 & 15,15 & 417 & 1,36 \\
BUKU 2 & 53 & 53,54 & 4.321 & 14,08 \\
BUKU 3 & 26 & 26,26 & 9.757 & 31,78 \\
BUKU 4 & 5 & 5,05 & 16.203 & 52,78 \\
\hline Total & $\mathbf{9 9}$ & $\mathbf{1 0 0}$ & $\mathbf{3 0 . 6 8 9}$ & $\mathbf{1 0 0}$ \\
\hline
\end{tabular}

Sumber: Otoritas Jasa Keuangan, 2017.

Tabel di atas menunjukkan bahwa mayoritas bank umum yang ada di Indonesia berada pada BUKU 2. Sementara BUKU 4 hanya terdiri dari 5 bank, namun jumlah unit kantor yang dimiliki mencapai lebih dari 50 persen jaringan kantor bank umum. Kelima bank BUKU 4 tersebut adalah: Bank Rakyat Indonesia (BRI), Bank Mandiri, Bank Negara Indonesia (BNI), Bank Central Asia (BCA), dan CIMB Niaga. Khusus untuk CIMB Niaga, tercatat sebagai bank umum kategori BUKU 4 sejak tahun 2017.

Kinerja perbankan merupakan gambaran tentang tingkat kesehatan bank, hal ini sangat penting karena menyangkut kepercayaan masyarakat kepada bank tersebut. Secara umum, penilaian tingkat kesehatan bank menggunakan metode CAMELS (Capital, Asset Quality, Management, Earnings, Liquidity, dan Sensitivity). Namun berdasarkan Surat Edaran Otoritas Jasa Keuangan Nomor 14/SEOJK.03/ 2017 tentang Penilaian Tingkat Kesehatan Bank Umum, metode yang digunakan untuk menilai tingkat kesehatan bank adalah metode RGEC (Risk profile, Good corporate governance, Earnings, dan Capital).

Otoritas Jasa Keuangan menetapkan beberapa faktor yang diukur dalam penilaian tingkat kesehatan bank, salah satunya adalah rentabilitas atau biasa disebut profitabilitas (earnings). Menurut Jusuf (2010), profitabilitas merupakan rasio yang menunjukkan kemampuan perusahaan mencetak laba. Dan bila dikaitkan dengan pemegang saham, maka rasio ini menunjukkan tingkat penghasilan investasi mereka. Salah satu parameter atau indikator dalam mengkur tingkat profitabilitas perbankan adalah Return on Asset. 
Published July 2018

Fill

EKONOMIKAWAN : Jurnal Ilmu Ekonomi dan Studi Pembangunan

ISSN : 1693-7600 (Print), ISSN : 2598-0157 (Online), http://jurnal.umsu.ac.id/index.php/ekawan

Berdasarkan tabel 2, dapat dilihat bahwa Return on Asset pada bank umum kategori BUKU 4 periode 2015-2017 memiliki kecenderungan menurun. Kecenderungan penurunan Return on Asset terjadi akibat terjadinya penurunan laba bersih yang diikuti dengan penambahan total aset, sehingga Return on Assetmenjadi cenderung menurun. Hal ini menimbulkan fenomena, dimana besarnya sasaran pembiayaan tidak diikuti dengan peningkatan Return on Asset.

Secara umum kinerja perbankan dipengaruhi oleh faktor internal dan eksternal. Messai et al. (2015) mengemukakan bahwa faktor internal fokus pada karakteristik spesifik keuangan bank, sementara faktor eksternal merupakan kondisi makroekonomi. Selain faktor internal yang merupakan karakteristik finansial bank itu sendiri, faktor eksternal diduga juga mempengaruhi profitabilitas khususnya bank umum kategori BUKU 4. Hal ini disebabkan kegiatan bisnis bank kategori BUKU 4 telah mencakup kegiatan usaha bank dengan kurs rupiah maupun valas, serta melakukan penyertaan modal pada lembaga keuangan di Indonesia dan/atau di seluruh wilayah luar negeri.

Tabel 2

Return on Asset Bank Umum Kategori BUKU 4 Periode 2015 - 2017

\begin{tabular}{cccccccc}
\hline \multirow{2}{*}{ No $\begin{array}{c}\text { Nama } \\
\text { Perusahaan }\end{array}$} & Tahun & \multicolumn{5}{c}{ Return on Asset (\%) } \\
\cline { 3 - 8 } & & TW I & TW II & TW III & TW IV & $\begin{array}{c}\text { Rata-rata } \\
\text { Perusahaan }\end{array}$ \\
\hline 1 & BCA & 2015 & 3,48 & 3,75 & 3,86 & 3,84 & 3,73 \\
& & 2016 & 3,57 & 3,86 & 3,99 & 3,96 & 3,85 \\
& & 2017 & 3,48 & 3,67 & 3,83 & - & 3,66 \\
\hline 2 & BNI & 2015 & 3,55 & 1,48 & 2,64 & 2,45 & 2,53 \\
& & 2016 & 3,03 & 2,16 & 2,51 & 2,69 & 2,60 \\
& & 2017 & 2,76 & 2,72 & 2,80 & - & 2,76 \\
\hline 3 & BRI & 2015 & 3,99 & 3,91 & 3,95 & 4,19 & 4,01 \\
& & 2016 & 3,65 & 3,68 & 3,59 & 3,84 & 3,69 \\
& & 2017 & 3,34 & 3,31 & 3,34 & - & 3,33 \\
\hline 4 & Bank & 2015 & 3,54 & 3,21 & 3,00 & 3,15 & 3,23 \\
& Mandiri & 2016 & 2,58 & 2,15 & 2,35 & 1,95 & 2,26 \\
& & 2017 & 2,38 & 2,61 & 2,72 & - & 2,57 \\
\hline
\end{tabular}

Sumber: Data Sekunder diolah, 2017

Messai et al. (2015) menyebutkan beberapa indikator yang mencerminkan karakteristik spesifik keuangan bank, seperti: CapitalAdequacy Ratio (CAR) danNonPerforming Loan (NPL). Sementara Siddiqua et al. (2017) juga menyebutkan bahwa Loan to Deposit Ratio (LDR)juga merupakan karakteristik spesifik keuangan bank.

Ong dan Teh (2013) menyebutkan bahwa faktor eksternal berkaitan dengan makroekonomi dan dapat dinilai dari beberapa indikator seperti tingkat inflasi, tingkat pertumbuhan Produk Domestik Bruto (PDB) dan kurs valuta asing. Sementara Dietrich dan Wanzeinried, (2011), menambahkan bahwa kebijakan moneter juga merupakan salah satu faktor eksternal. Atas dasar pemikiran yang telah dipaparkan, maka penulismelakukan penelitian pengaruh faktor internal dan faktor eksternal terhadap kinerja perbankan pada bank umum yang terdaftar di Bursa Efek Indonesia. 
Published July 2018

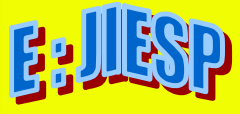

EKONOMIKAWAN : Jurnal Ilmu Ekonomi dan Studi Pembangunan

ISSN : 1693-7600 (Print), ISSN : 2598-0157 (Online), http://jurnal.umsu.ac.ld/index.php/ekawan

\section{METODE}

Penelitian ini dilakukan untuk melihat pengaruh faktor internal melalui indikator Capital Adequacy Ratio (CAR), Loan to Deposit Ratio (LDR), Non-Performing Loan (NPL) dan faktor eksternal melalui indikator tingkat inflasi, tingkat pertumbuhan Produk Domestik Bruto, BI Rate terhadap kinerja perbankan yang diukur melalui Return on Asset (ROA) baik secara parsial maupun simultan. Adapun kerangka konseptual penelitian dapat dilihat pada gambar dibawah ini:

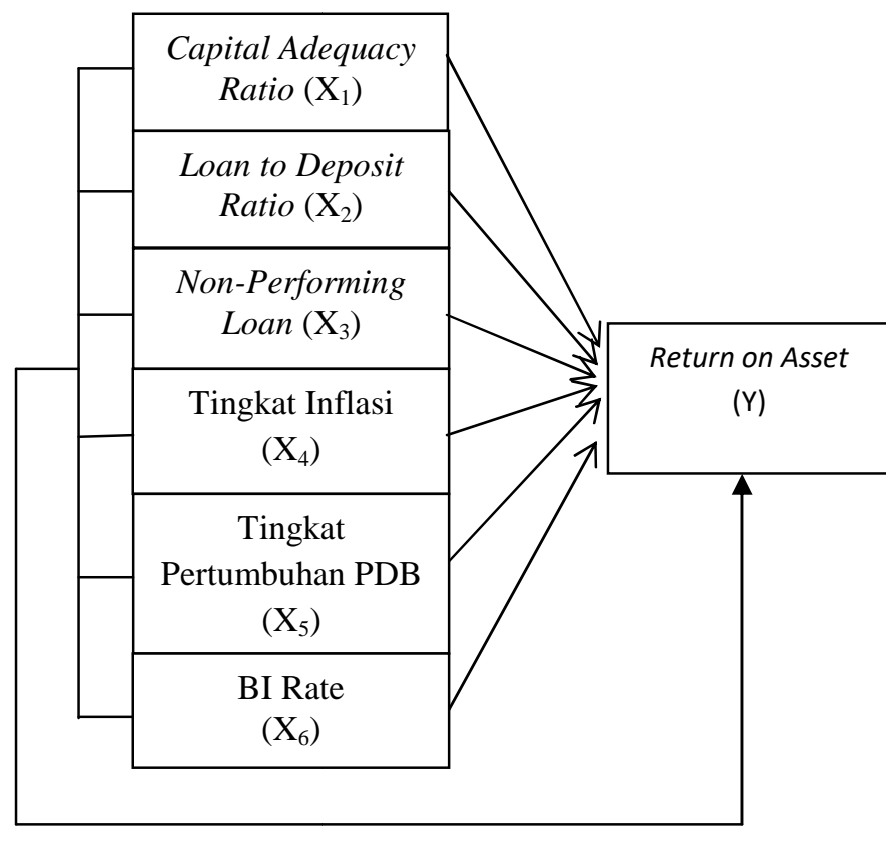

Gambar 1

Kerangka Konseptual Penelitian

Penelitian ini menggunakan metode asosiatif dengan menggunakan purposive sampling untuk memperoleh data sekunder. Sampel penelitian dipilih berdasarkan kriteria berikut: 1) Perusahaan perbankan umum yang listed terus menerus di Bursa Efek Indonesia sepanjang tahun amatan 2015-2017, dan 2) Perusahaan perbankan umum yang saat ini masuk ke dalam kategori BUKU 4. Data yang diperoleh diolah menggunakan analisis regresi linier berganda menggunakan software SPSS v.24.

Regresi berganda merupakan salah satu alat dalam statistik parametrik dan pemakaiannya perlu mempertimbangkan sifat distribusi data yang diolah. Teknik ini digunakan apabila penelitiingin membuat prediksi berdasarkan model yang telah diketahui atauingin menentukan kekuatan hubungan (asimetris) antara variabel dependen dengan variabel independen dimana variabel dependen diukur dengan skala matriks seperti skala rasio atau minimal skala interval (Gudono, 2015).Berdasarkan hasil analisis regresi linier berganda diperoleh persamaan regresi sebagai berikut: 
EKONOMIKAWAN : Jurnal Ilmu Ekonomi dan Studi Pembangunan ISSN : 1693-7600 (Print), ISSN : 2598-0157 (Online), http://jurnal.umsu.ac.Id/index.php/ekawan

$$
Y=a+b_{1} X_{1}+b_{2} X_{2}+b_{3} X_{3}+b_{4} X_{4}+b_{5} X_{5}+b_{6} X_{6}
$$

Keterangan :

$\mathrm{a}=$ Konstanta

$\mathrm{b}_{1}=$ koefisien Capital Adequacy Ratio

$\mathrm{b}_{2}=$ koefisien Loan to Deposit Ratio

$\mathrm{b}_{3}=$ koefisien Non-Performing Loan

$\mathrm{b}_{4}=$ koefisien Tingkat Inflasi

$\mathrm{b}_{5}=$ koefisien Tingkat Pertumbuhan PDB

$\mathrm{b}_{6}=$ koefisien BI Rate

Sebelum melakukan pengujian hipotesis yang diajukan dalam penelitian ini, perlu dilakukan pengujian asumsi klasik yang meliputi Uji Normalitas, Uji Multikolinieritas, dan Uji Heterokedastisitas. Hipotesis pada penelitian ini akan dilakukan pengujian secara parsial (Uji t), secara simultan (Uji F), dan uji ketepatan model / koefisien determinasi (Uji $\mathrm{R}^{2}$ ).

\section{HASIL PENELITIAN DAN PEMBAHASAN}

Analisis deskriptif dari data yang diambil untuk penelitian ini adalah dari tahun 2015 sampai dengan tahun 2017 yaitu sebanyak 44 data pengamatan. Deskriptif variabel dalam statistik deskriptif yang digunakan pada penelitian ini meliputi mean dan standar deviasi dari satu variabel dependen dan enam variabel independen.

\section{Tabel 3}

\begin{tabular}{|c|c|c|}
\hline Variabel & Mean & Std. Deviation \\
\hline $\mathrm{Y}$ & 3,1934 & ,66438 \\
\hline$X_{1}$ & 20,1864 & 1,71414 \\
\hline $\mathrm{X}_{2}$ & 85,2302 & 5,51203 \\
\hline$X_{3}$ & ,6832 & ,31828 \\
\hline $\mathrm{X}_{4}$ & 4,6718 & 1,47084 \\
\hline $\mathrm{X}_{5}$ & 1,5645 & 2,31398 \\
\hline $\mathrm{X}_{6}$ & 6,1891 & 1,27282 \\
\hline
\end{tabular}

Sumber: Hasil Penelitian diolah, 2018

\section{Regresi Linier Berganda}

\section{Uji Normalitas}

Uji ini digunakan untuk mengetahui apakah model regresi variabel pengganggu atau residual memiliki distribusi normal. Uji normalitas yang digunakan dalam penelitian ini yaitu Normal P-P Plot of Regression Standardized Rasidual. 


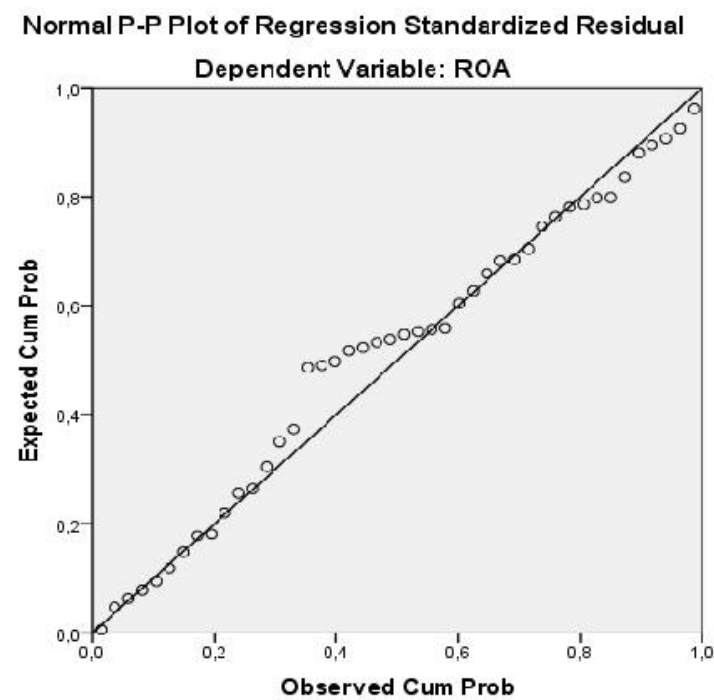

Gambar 2

Hasil Uji Normal P-P Plot of Regression Standardized Rasidual

Berdasarkan grafik normal p-plot diatas, dapat dilihat bahwa titik-titik mengikuti dan menyebar digaris diagonal. Maka dari itu, grafik normal p-plot dinyatakan berdistribusi normal sehingga memenuhi kriteria asumsi normalitas.

\section{Uji Multikolinearitas}

Uji ini bertujuan untuk menguji apakah model regresi ditemukan adanya korelasi antar variabel bebas. Uji multikolinearitas dapat dilihat dari: nilai tolerance dan lawannya, dan Variance Inflation Factor (VIF). Jika nilai tolerance lebih besar dari 0,1 atau nilai VIF lebih kecil dari 10, maka dapat disimpulkan tidak terjadi multikolinearitas pada data yang akan diolah.

\section{Tabel 4}

Hasil Uji Moltikolinearitas

\begin{tabular}{crr}
\hline Variabel & Tollerance & \multicolumn{1}{c}{ VIF } \\
\hline $\mathrm{X}_{1}$ &, 406 & 2,462 \\
$\mathrm{X}_{2}$ &, 396 & 2,523 \\
$\mathrm{X}_{3}$ &, 432 & 2,313 \\
$\mathrm{X}_{4}$ &, 330 & 3,027 \\
$\mathrm{X}_{5}$ &, 906 & 1,104 \\
$\mathrm{X}_{6}$ &, 380 & 2,635 \\
\hline \multicolumn{3}{l}{ Sumber: Hasil Penelitian diolah, 2018 }
\end{tabular}

Dari data pada tabel diatas, dapat diketahui bahwa nilai VIF untukX $\mathrm{X}_{1}$ sebesar 2,462, $\mathrm{X}_{2}$ sebesar 2,523, $\mathrm{X}_{3}$ sebesar 2,313, $\mathrm{X}_{4}$ sebesar 3,027, $\mathrm{X}_{5}$ sebesar 1,104, dan $\mathrm{X}_{6}$ sebesar 2,635. Dari masing - masing variabel yang diuji nilai VIF nya, tidak ada variabel independen yang nilainya lebih dari 10 . 
Published July 2018

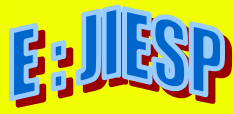

EKONOMIKAWAN : Jurnal Ilmu Ekonomi dan Studi Pembangunan

ISSN : 1693-7600 (Print), ISSN : 2598-0157 (Online), http://jurnal.umsu.ac.ld/index.php/ekawan

Begitu juga dengan nilai tollerance pada $X_{1}$ sebesar $0,406, X_{2}$ sebesar $0,396, X_{3}$ sebesar 0,432, $\mathrm{X}_{4}$ sebesar 0,330, $\mathrm{X}_{5}$ sebesar 0,906, dan $\mathrm{X}_{6}$ sebesar 0,380. Dari masing masing variabel yang diuji nilai tolerance lebih dari 0,1 . Dari hasil uji yang ada, dapat disimpulkan bahwa tidak terjadi gejala multikolinearitas antara variabel independen yang diindikasikan dari nilai tolerance setiap variabel independen yang lebih besar dari 0,1 dan nilai VIF yang lebih kecil dari 10. Maka dapat disimpulkan bahwa analisis lebih lanjut dapat dilakukan dengan menggunakan model regresi berganda.

\section{Uji Heterokedastisitas}

Uji ini digunakan agar mengetahui adanya ketidaksamaan varians dari residual satu pengamatan ke pengamatan lain dalam sebuah model regresi. Bentuk pengujian yang digunakan dengan metode informal atau grafik scatterplot. Adapun dasar analisis adalahmenurut Ghozali (2005), yaitu : Jika ada pola tertentu, seperti titik - titik yang ada membentuk pola tertentu yang teratur (bergelombang, melebar kemudian menyempit), maka mengindikasikan telah terjadi heterokedastisitas. Namun Jika tidak ada pola yang jelas, serta titik - titik menyebar diatas dan di bawah angka nol (0) pada sumbu Y, maka tidak terjadi heterokedastisitas.

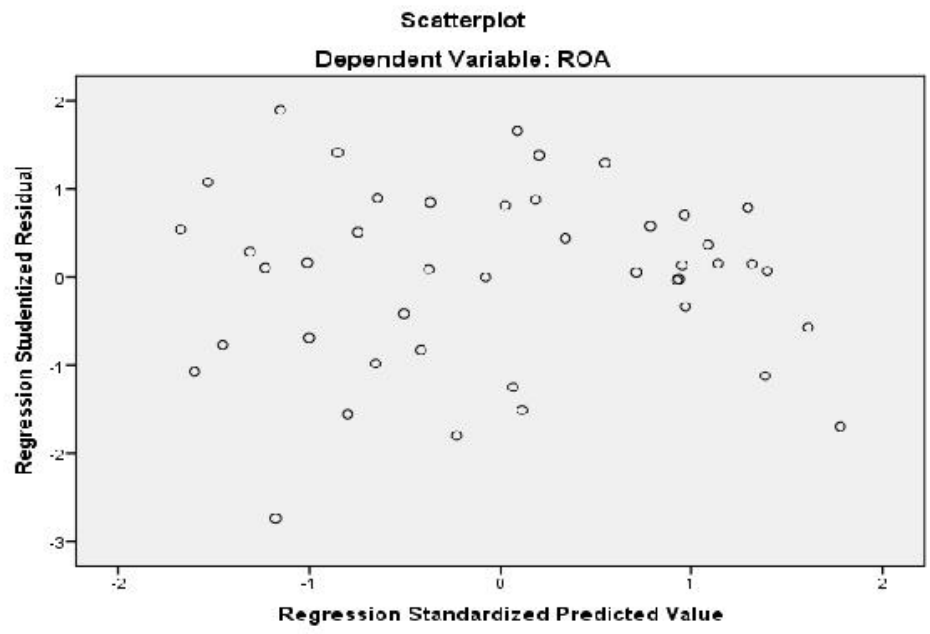

Gambar 3. Hasil Uji Heterokedastisitas

Dari grafik scatterplot terlihat bahwa jika ada pola yang jelas, serta titik-titik menyebar di atas dan di bawah angka 0 pada sumbu Y, maka mengindikasikan terjadi heterokedastisitas. Hal ini dapat disimpulkan bahwa tidak terjadi heterokedastisitas pada model regresi sehingga model regresi layak dipakai untuk melihat Return on Asset perusahaan perbankan yang terdaftar di Bursa Efek Indonesia berdasarkan masukan variabel independen Capital Adequacy Ratio, Loan to Deposit Ratio, Non-Performing Loan, tingkat inflasi, tingkat pertumbuhan PDB, dan BI Rate.

\section{Analisis Regresi Linier Berganda}

Setelah data dilakukan uji asumsi klasik dan diperoleh data yang berdistribusi normal, tidak terjadi multikolinearitas, dan tidak terjadi heterokedastitas, maka selanjutnya data dapat dianalisis dengan analisis regresi linear berganda. Berikut hasil pengolahan data dengan menggunakan SPSS v24. 
Published July 2018

EKONOMIKAWAN : Jurnal Ilmu Ekonomi dan Studi Pembangunan

ISSN : 1693-7600 (Print), ISSN : 2598-0157 (Online), http://jurnal.umsu.ac.Id/index.php/ekawan

Tabel 5

Hasil Analisis Regresi Linier Berganda

\begin{tabular}{|c|c|c|c|c|c|}
\hline \multirow[b]{2}{*}{ Model } & \multicolumn{2}{|c|}{ Unstandarized Coefficients } & \multirow{2}{*}{$\begin{array}{c}\text { Standarized } \\
\text { Coefficients Beta }\end{array}$} & \multirow[b]{2}{*}{$\mathbf{t}$} & \multirow[b]{2}{*}{ Sig. } \\
\hline & $\mathbf{B}$ & Std. Error & & & \\
\hline (Constant) & $-5,055$ & 2,565 & & $-1,971$ & ,056 \\
\hline $\mathrm{X}_{1}$ & ,308 & ,060 & ,794 & 5,123 & ,000 \\
\hline $\mathrm{X}_{2}$ &, 022 & 019 & ,186 & 1,184 &, 244 \\
\hline $\mathrm{X}_{3}$ & $-1,516$ & ,313 &,- 726 & $-4,839$ &, 000 \\
\hline $\mathrm{X}_{4}$ &, 187 & ,078 & ,415 & 2,414 &, 021 \\
\hline $\mathrm{X}_{5}$ &,- 052 & ,030 &,- 182 & $-1,757$ & ,087 \\
\hline $\mathrm{X}_{6}$ &, 061 & ,084 &, 116 &, 726 & ,472 \\
\hline
\end{tabular}

Sumber: Hasil Penelitiandiolah, 2018

Dari tabel diatas, maka diketahui nilai-nilai sebagai berikut:

$a=-5,055 \quad b_{4}=0,187$

$b_{1}=0,308 \quad b_{5}=-0,052$

$b_{2}=0,022 \quad b_{6}=0,061$

$b_{3}=-1,516$

Bila hasil tersebut dimasukkan ke dalam persamaan regresi linier berganda, maka akan diperoleh persamaan sebagai berikut:

$$
Y=-5,055+0,308 X_{1}+0,022 X_{2}-1,516 X_{3}+0,187 X_{4}-0,052 X_{5}+0,061 X_{6}
$$

\section{Uji Hipotesis}

\section{Uji secara Parsial (Uji t)}

Uji statistik t dilakukan untuk menguji apakah variabel bebas $(\mathrm{X})$ secara individual mempunyai hubungan yang signifikan atau tidak terhadap variabel terikat (Y). Kriteria Uji t dilakukan dengan taraf signifikansi sebesar 5\% $(\alpha=0,05)$, sehingga diperoleh nilai ttabel sebesar 2,027. Untuk menentukan signifikan atau tidaknya nilai tersebut dapat dilihat dengan membandingkan t-hitung dengan t-tabel, dengan ketentuan: Apabila t-hitung $\leq \mathrm{t}$ tabel $\leq \mathrm{t}$-hitung, maka $\mathrm{H}_{0}$ diterima dan $\mathrm{H}_{\mathrm{a}}$ ditolak yang berarti signifikan. Namun, Apabila t-tabel $\leq$ t-hitung $\leq$ t-tabel, maka $\mathrm{H}_{0}$ ditolak dan $\mathrm{H}_{\mathrm{a}}$ diterima yang berarti tidak signifikan.

Tabel 6

\section{Hasil Uji t}

\begin{tabular}{cll}
\hline Variabel & \multicolumn{1}{c}{ Hasil } & \multicolumn{1}{c}{ Keterangan } \\
\hline $\mathrm{X}_{1}$ & $\mathrm{H}_{0}$ ditolak & Signifikan \\
$\mathrm{X}_{2}$ & $\mathrm{H}_{0}$ diterima & Tidak Signifikan \\
$\mathrm{X}_{3}$ & $\mathrm{H}_{0}$ ditolak & Signifikan \\
$\mathrm{X}_{4}$ & $\mathrm{H}_{0}$ ditolak & Signifikan \\
$\mathrm{X}_{5}$ & $\mathrm{H}_{0}$ diterima & Tidak Signifikan \\
$\mathrm{X}_{6}$ & $\mathrm{H}_{0}$ diterima & Tidak Signifikan \\
\hline
\end{tabular}

Sumber: Hasil Penelitian diolah, 2018 
Published July 2018

Fid]

EKONOMIKAWAN : Jurnal Ilmu Ekonomi dan Studi Pembangunan

ISSN : 1693-7600 (Print), ISSN : 2598-0157 (Online), http://jurnal.umsu.ac.Id/index.php/ekawan

Dari hasil uji t menunjukkan bahwa variabel Capital Adequacy Ratio berpengaruh positif dan signifikan terhadap Return on Asset, Non-Performing Loan dan tingkat inflasiberpengaruh negatif dan signifikan terhadap Return on Asset, serta Loan to Deposit Ratio, tingkat pertumbuhan PDB, dan BI Rate tidak berpengaruh signifikan terhadap Return on Assetpada perusahaan perbankan yang terdaftar di Bursa Efek Indonesia.

\section{Uji secara Simultan (Uji F)}

Uji F menunjukkan apakah semua variabel independen atau bebas yang dimasukkan dalam model, mempunyai pengaruh secara bersama - sama (simultan) terhadap variabel dependen. Kriteria Uji F dilakukan dengan taraf signifikansi sebesar 5\% $(\alpha=0,05)$, sehingga diperoleh nilai F-tabel sebesar 2,374. Sementara dari hasil ANOVA, diperoleh nilai F-hitung sebesar 10,938. Untuk menentukan berpengaruh atau tidaknya variabel independen dapat dilihat dengan membandingkan F-hitung dengan F-tabel, dengan ketentuan: Apabila F-hitung $\geq$ F-tabel, maka $\mathrm{H}_{0}$ ditolak dan $\mathrm{H}_{\mathrm{a}}$ diterima yang berarti signifikan. Namun, Apabila F-hitung $\leq$ F-tabel, maka $\mathrm{H}_{0}$ diterima dan $\mathrm{H}_{\mathrm{a}}$ ditolak yang berarti tidak signifikan.

Berdasarkan hasil ANOVA (Analysis of Variance) pada tabel diatas, diperoleh bahwa F-hitung $\geq$ F-tabel, sehingga dapat disimpulkan bahwa Capital Adequacy Ratio, Loan to Deposit Ratio, Non-Performing Loan, tingkat inflasi, tingkat pertumbuhan PDB, dan BI Rate berpengaruh secara simultan berpengaruh signifikan terhadap Return on Assetpada perusahaan perbankan kategori BUKU 4 yang terdaftar di Bursa Efek Indonesia.

\section{Koefisien Determinasi (Uji $\mathbf{R}^{2}$ )}

Koefisien determinasi ini berfungsi untuk mengetahui persentase besarnya pengaruh variabel independen dan variabel dependen yaitu dengan mengkuadratkan koefisien yang ditemukan. Adapun hasil penentuan koefisien determinasi (Uji $\mathrm{R}^{2}$ ) adalah sebagi berikut:

\section{Tabel 7}

\section{Hasil Uji $\mathbf{R}^{2}$}

\begin{tabular}{|c|c|c|c|}
\hline Model & $R$ & $\begin{array}{c}\boldsymbol{R} \\
\text { Square }\end{array}$ & $\begin{array}{c}\text { Std. Error } \\
\text { of the } \\
\text { Estimate }\end{array}$ \\
\hline 1 & ,800 & ,639 & ,43005 \\
\hline
\end{tabular}

Pada tabel diatas, dapat diketahui hasil analisis regresi secara kontribusi menunjukkan Nilai $R$ Square atau koefisien - koefisien adalah 0,639. Angka ini mengidentifikasikan bahwa Return on Asset(variabel dependen) mampu dijelaskan oleh Capital Adequacy Ratio, Loan to Deposit Ratio, Non-Performing Loan, tingkat inflasi, tingkat pertumbuhan PDB, dan BI Rate(variabel independen) sebesar 63,9\%. Sedangkan selebihnya $36,1 \%$ dijelaskan oleh sebab - sebab lain yang tidak diketahui dalam penelitian ini.

Standard Error of the Estimate adalah sebesar 0,43005 yang nilainya lebih kecil dari Standard Deviation pada tabel 3, yaitu sebesar 0,66438. Hal ini menunjukkan bahwa model regresi lebih baik dalam bertindak sebagai prediktor Return on Assetdibandingkan dengan rata-rata Return on Assetitu sendiri. 
Published July 2018

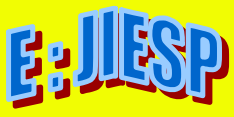

EKONOMIKAWAN : Jurnal Ilmu Ekonomi dan Studi Pembangunan

ISSN : 1693-7600 (Print), ISSN : 2598-0157 (Online), http://jurnal.umsu.ac.Id/Index.php/ekawan

\section{Pembahasan}

Hasil uji hipotesis pertama menunjukkan Capital Adequacy Ratio berpengaruh signifikan dengan arah positif terhadapReturn on Assetpada perusahaan perbankan kategori BUKU 4 yang terdaftar di Bursa Efek Indonesia. Penelitian ini sejalan dengan penelitian yang dilakukan oleh Messai et al. (2015) pada bank yang terdapat di Eropa Barat dan oleh Sabir (2012) pada bank di Indonesia, menunjukkan bahwa terdapat pengaruh yang positif dan signifikan antara Capital Adequacy Ratioterhadap Return on Asset. Dari hasil penelitian diatas menunjukkan kenaikan Capital Adequacy Ratiodari tahun ke tahun mempengaruhi nilai Return on Asset. Meningkatnya Capital Adequacy Ratio menunjukkan jumlah modal pada perusahaan perbankan meningkat apabila dibandingkan dengan Aktiva Tertimbang Menurut Risiko (ATMR), sehingga hal ini akan berdampak pada besarnya peluang ekspansi bisnis yang dimiliki bank.

Hasil uji hipotesis kedua menunjukkan Loan to Deposit Ratio tidak berpengaruh signifikan terhadapReturn on Assetpada perusahaan perbankan kategori BUKU 4 yang terdaftar di Bursa Efek Indonesia. Penelitian ini sejalan dengan penelitian yang dilakukan oleh Abdullah dan Jahan (2014) pada bank yang terdapat di Bangladesh, namun tidak sejalan dengan penelitian yang dilakukan oleh Rangasamy (2014) pada bank yang terdapat di Malaysia dan oleh Siddiqua et al. (2016) pada bank di Bangladesh. Idealnya, semakin tinggi Loan to Deposit Ratio, maka semakin banyak volume kredit yang dilemparkan. Sementara pendapatan bunga kredit merupakan sumber pendapatan utama bank. Namun, apabila tingginya volume kredit yang dilemparkan tidak diikuti dengan kualitas kredit yang dilemparkan, maka tidak akan terjadi peningkatan Return on Assetyang signifikan.

Hasil uji hipotesis ketiga menunjukkan Non-Performing Loan berpengaruh signifikan dengan arah negatif terhadapReturn on Assetpada perusahaan perbankan kategori BUKU 4 yang terdaftar di Bursa Efek Indonesia. Penelitian ini sejalan dengan penelitian yang dilakukan oleh Messai et al. (2015) pada bank yang terdapat di Eropa Barat dan oleh Sabir (2012) pada bank di Indonesia, menunjukkan bahwa terdapat pengaruh yang negatif dan signifikan antara Non-Performing Loanterhadap Return on Asset. Dari hasil penelitian diatas menunjukkan kenaikan Capital Adequacy Ratiodari tahun ke tahun mempengaruhi nilai Return on Asset.

Kenaikan Non-Performing Loanberpengaruh terhadap penurunan Return on Asset. Penurunan Return on Asset akan mengakibatkan penurunan profitabilitas bank yang disebabkan akibat pembentukan Cadangan Kerugian Penurunan Nilai (CKPN) karena kredit bermasalah. CKPN sendiri diambil dari laba, sehingga pembentukan CKPN akan mengurangi laba perusahaan dan mengakibatkan penurunan Return on Asset.

Hasil uji hipotesis keempat menunjukkan tingkat inflasi berpengaruh signifikan dengan arah negatif terhadapReturn on Assetpada perusahaan perbankan kategori BUKU 4 yang terdaftar di Bursa Efek Indonesia. Messai et al. (2015) pada bank yang terdapat di Eropa Barat, namun tidak sejalan dengan penelitian yang dilakukan oleh Abreu dan Mendes (2002) pada bank yang terdapat di Uni Eropa. Kenaikan tingkat inflasi akan menyebabkan kenaikan harga, sehingga hal ini akan meningkatkan pendapatan debitur bank dan akan memudahkan debitur dalam membayar kewajibannya kepada bank. Hal ini berdampak pada pendapatan bank yang juga akan meningkat. 
Published July 2018

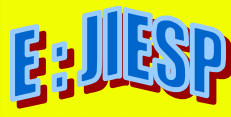

EKONOMIKAWAN : Jurnal Ilmu Ekonomi dan Studi Pembangunan

ISSN : 1693-7600 (Print), ISSN : 2598-0157 (Online), http://jurnal.umsu.ac.ld/index.php/ekawan

Hasil uji hipotesis kelima menunjukkan tingkat pertumbuhan PDB tidak berpengaruh signifikan terhadapReturn on Assetpada perusahaan perbankan kategori BUKU 4 yang terdaftar di Bursa Efek Indonesia. Penelitian ini sejalan dengan penelitian yang dilakukan oleh Ong dan Teh (2013) pada bank yang terdapat di Malaysia, namun tidak sejalan dengan penelitian yang dilakukan oleh Ali et al. (2011) pada bank yang terdapat di Pakistan.

Hasil uji hipotesis keenam menunjukkan BI Rate tidak berpengaruh signifikan terhadapReturn on Assetpada perusahaan perbankan kategori BUKU 4 yang terdaftar di Bursa Efek Indonesia. Penelitian ini tidak sejalan dengan penelitian yang dilakukan oleh Amaliawati dan Winarso (2012) dan oleh Kesumayuda dkk (2015) yang menunjukkan adanya pengaruh positif dan signifikan antara BI Rate terhadap Return on Asset.Namun penelitian ini sejalan dengan penelitian yang dilakukan oleh Irwadi (2014).BI Rate merupakan respon bank sentral terhadap gejolak makroekonomi. Namun BI Rate cenderung stabil, sementara terjadi fluktuasi pada faktor makroekonomi lainnya seperti tingkat inflasi dan tingkat pertumbuhan PDB. Hal ini mengakibatkan tidak signifikannya efek BI Rate terhadap Return on Asset.

Hasil uji hipotesis ketujuh menunjukkan adanya pengaruh signifikan antara Capital Adequacy Ratio, Loan to Deposit Ratio, Non-Performing Loan, tingkat inflasi, tingkat pertumbuhan PDB, dan BI Rate terhadapReturn on Assetsecara simultan pada perusahaan perbankan kategori BUKU 4 yang terdaftar di Bursa Efek Indonesia. Hal ini berarti faktor internal dan eksternal erat kaitannya dengan profitabilitas bank. Kemudian dengan tingkat hubungan sebesar 63,9\%.yang berarti ada 36,1\% dipengaruhi oleh faktor lain seperti, faktor internal berupa rasio BOPO (Beban Operasional per Pendapatan Operasional) dan faktor eksternal berupa tingkat pengangguran dan jumlah uang beredar. Berdasarkan dari hasil penelitian diatas, maka penulis dapat menyimpulkan bahwa ada kesesuaian antara hasil penelitian, teori dengan pendapat dan penelitian terdahulu, yakni Capital Adequacy Ratio, Loan to Deposit Ratio, Non-Performing Loan, Tingkat Inflasi, Tingkat Pertumbuhan PDB dan BI Rate berpengaruh secara simultan terhadap Return on Assetpada perusahaan perbankan kategori BUKU 4 yang terdaftar di Bursa Efek Indonesia.

\section{SIMPULAN}

Berdasarkan hasil dan pembahasan, dapat dirumuskan kesimpulan sebagai berikut. Capital Adequacy Ratio berpengaruh positif dan signifikan terhadap Return on Assetpada perusahaan perbankan kategori BUKU 4 yang terdaftar di Bursa Efek Indonesia. Loan to Deposit Ratiotidak berpengaruh signifikan terhadap Return on Assetpada perusahaan perbankan kategori BUKU 4 yang terdaftar di Bursa Efek Indonesia. Non-Performing Loan berpengaruh negatif dan signifikan terhadap Return on Assetpada perusahaan perbankan kategori BUKU 4 yang terdaftar di Bursa Efek Indonesia. Tingkat inflasi berpengaruh positif dan signifikan terhadap Return on Assetpada perusahaan perbankan kategori BUKU 4 yang terdaftar di Bursa Efek Indonesia. Tingkat pertumbuhan PDB tidak berpengaruh signifikan terhadap Return on Assetpada perusahaan perbankan kategori BUKU 4 yang terdaftar di Bursa Efek Indonesia. BI Rate tidak berpengaruh signifikan terhadap Return on Assetpada perusahaan perbankan kategori BUKU 4 yang terdaftar di Bursa Efek Indonesia. 
Published July 2018



EKONOMIKAWAN : Jurnal Ilmu Ekonomi dan Studi Pembangunan

ISSN : 1693-7600 (Print), ISSN : 2598-0157 (Online), http://jurnal.umsu.ac.ld/index.php/ekawan

\section{SARAN}

Berdasarkan kesimpulan diatas, beberapa saran yang dapat disampaikan sebagai berikut. 1) Dalam pengelolaan bisnis, sebaiknya bank memperhatikan aspek permodalan karena rasio kecukupan modal merupakan aspek yang berpengaruh siginifikan terhadap profitabilitas bank. 2) Sebaiknya bank memperhatikan rasio Loan to Deposit Ratioyang merupakan aspek likuditas bank, sehungga bank tidak melempar kredit dengan volume yang jauh lebih besar dibandingkan dengan dana pihak ketiga yang dihimpun. 3) Sebaiknya bank memperhatikan kualitas kredit yang dilemparkan karena pemburukan kualitas kredit dapat berpengaruh signifikan terhadap penurunan laba akibat pembentukan CKPN. 4) Selain faktor internal, bank juga sebaiknya memperhatikan tingkat inflasi dalam menjalankan bisnis. Hal ini dikarenakan tingkat inflasi dapat mempengaruhi profitabilitas bank secara signifikan. 5) Sebaiknya bank juga memperhatikan tingkat pertumbuhan Produk Domestik Bruto (PDB) yang merupakan indikator pertumbuhan ekonomi secara riil, meskipun dampaknya tidak signifikan terhadap sektor perbankan. 6) Sebaiknya bank juga memperhatikan BI Rate dalam menjalankan bisnisnya karena BI Rate dapat mempengaruhi profitabilitas bank meskipun tidak secara signifikan. 7) Untuk penelitian selanjutnya disarankan agar menggunakan Non-Performing Loan sebagai variabel moderating, menggunakan indikator faktor internal dan eksternal yang lain seperti: rasio Beban Operasional per Pendapatan Operasional (BOPO) dan kenaikan jumlah uang yang beredar, serta menggunakan indikator profitabilitas yang lain seperti Return on Equity (ROE) dan Net Interest Margin (NIM).

\section{DAFTAR PUSTAKA}

Abdullah, Mohammad Nayeen dan Jahan, Nusrat. (2014). "The Impact of Liquidity on Profitability in Banking Sector of Bangladesh: A Case of Chittagong Stock Exchange". EPRA International Journal of Economic and Business Review. Vo. 2 No. 10. p. $17-22$

Abreu, Margarida dan Mendes, Victor. (2002). "Commercial Bank Interest Margins and Profitabiliy: Evidence for Some EU Countries". Porto Working Paper Series

Ali, Khizer., Akhtar, Muhammad Farhan., dan Ahmed, Hafiz Zafar. (2011). "BankSpecific and Macroeconomic Indicators of Profitability - empirical evidence from the Commercial Banks of Pakistan". International Journal of Business and Social Science. Vol. 2 No. 6. p. 235 - 242

Amaliawati, Lia dan Winarso, Edi. (2012). "The Influence of Monetary Policy (BI Rate) on Profitability of Commercial Banks in Indonesia". 10th Ubaya International Annual Symposium on Management. p. 1344 -1361

Dendawijaya, Lukman. (2005). “Manajemen Perbankan". Ghalia Indonesia, Bogor

Dietrich, Andreas., and Wanzenried, Gabrielle. (2011). "Determinants of Bank Profitability before and during The Crisis: Evidence from Switzerland". Journal of International Financial Markets, Institutions \& Money. Vol. 21. p. 307 - 327

Ghozali, Imam (2005). "Aplikasi Analisis Multivariate dengan program SPSS". Edisi 3. Badan Penerbit UNDIP, Semarang

Gudono (2015). "Analisis Data Multivariat". Edisi 4. BPFE-Yogyakarta, Yogyakarta

Hanafi, Mamduh M., dan Halim, Abdul. (2007). "Analisis Laporan Keuangan". PT. Rajagrafindo Persada, Jakarta 
Published July 2018

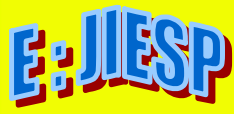

EKONOMIKAWAN : Jurnal Ilmu Ekonomi dan Studi Pembangunan

ISSN : 1693-7600 (Print), ISSN : 2598-0157 (Online), http://jurnal.umsu.ac.ld/index.php/ekawan

Irwadi, Maulan. (2014). "Pengaruh Inflasi dan BI Rate terhadap Laba Perbankan di Indonesia”. Jurnal OCPUS. Vol. VI. No. 2. Hal.44 - 58.

Ismail. (2009). "Akuntansi Bank Teori dan Aplikasi". Kencana, Jakarta.

Jusuf, Jopie (2010). "Analisis Kredit untuk Credit (Account) Officer”. Gramedia, Jakarta.

Kasmir. (2017). “Analisis Laporan Keuangan”. Edisi 1. Rajawali Pers, Jakarta

Kesumayuda, I.B.N., Utama, M.S., dan Purbadharmaja, I.B.P. (2016). "Analisis Faktor Internal dan Eksternal yang Mempengaruhi Kinerja Keuangan Bank Pembangunan Daerah di Indonesia Periode 2010-2013”. Jurnal Buletin Studi Ekonomi. Vol. 21 No. 1. Hal. 26-37.

Kuncoro, Mudrajad. (2013). "Mudah Memahami \& Menganalisis Indikator Ekonomi". UPP STIM YKPN, Yogyakarta.

Messai, A.S., Gallali, M.I., and Jouini, F. (2015).” Determinants of Bank Profitability in Western European Countries Evidence from System GMM Estimates". International Business Research. Vol. 8 No. 7. p. 30-42.

Ong T.S. and Teh B.H. (2013). "Factors Affecting the Profitability of Malaysian Commercial Banks". African Journal of Business Management. Vol. 7 No. 8. p. 649660.

Otoritas Jasa Keuangan. (2017). “Statistik Perbankan Indonesia September 2017”. Statistik Perbankan Indonesia. Vol. 15 No. 10.

Peraturan Otoritas Jasa Keuangan Nomor 6/POJK.03/2016 Tanggal 26 Januari 2016 tentang Kegiatan Usaha dan Jaringan Kantor Berdasarkan Modal Inti Bank.

Rangasamy, Dhanuskodi. (2014). "Impact of Loan Deposit Ratio on Profitability: Panel Evidence from Commercial Banks in Malaysia". Proceedings of the Third International Confrence on Global Business, Economics, Finance, and Social Science. p. $1-13$

Rivai Veithzal., Modding, Basri., Veithzal, Andria Permata., dan Mariyanti, Tatik. (2013). "Financial Institution Management (Manajemen Kelembagaan Keuangan)". Edisi 1. PT. Rajagrafindo Persada, Jakarta.

Sabir, Muh. M., Ali, Muhammad dan Habbe, Abd. Hamid. (2012). "Pengaruh Rasio Kesehatan Bank terhadap Kinerja Keuangan Bank Umum Syariah dan Bank Konvensional di Indonesia”. Jurnal Analisis. Vol. 1 No. 1. Hal. 79 - 86.

Siddiqua, A., Chowdhury, A.N.M.M., Chowdhury, A.S.M.M.H., Mainuddin, M., and Rahman, M.L. (2017). "Impact of Internal Factors on the Profitability of Banks: A Case of Commercial Banks in Bangladesh". Asian Business Review. Vol. 7 No. 1. p.63-71.

Taswan. (2006). "Manajemen Perbankan: Konsep, Teknik dan Aplikasi". UPP YKN, Yogyakarta. 